\title{
Homogenous Acidic and Basic Catalysts in Biodiesel Synthesis: A Review
}

\author{
Abdelmalik M. Shakorfowa and Abdulaziz. H. Mohamed ${ }^{\mathrm{b}}$ \\ aChemical and Petroleum Engineering Department, Faculty of Engineering, Elmergib University, Khoms-Libya \\ ${ }^{\mathrm{b} C h e m i c a l ~ E n g i n e e r i n g ~ D e p a r t m e n t, ~ F a c u l t y ~ o f ~ E n g i n e e r i n g, ~ T o b r u k ~ U n i v e r s i t y, ~ T o b r u k-L i b y a ~}$ \\ *Corresponding Author E-mail: Dr_Eng.Malik@Yahoo.Co.Uk
}

\section{DOI: 10.2478/acmy-2020-0013}

\begin{abstract}
:
Several techniques, in which different homogenous catalysts and procedures, that are in use for transesterification of a vegetable oil or an animal fat have been successful in synthesizing biodiesel, although with some certain limitations. For such a purpose, among the catalysts employed are acidic as well as basic catalysts. It has been found that acidic catalysts can be tolerant with a high content of free fatty acids found in those low value feedstock oils/fats to be transesterified, although some sort of pretreatment by means of esterification might be required in order to synthesize biodiesel. Moreover, with employing homogenous acidic catalysts, it seems that biodiesel purification procedures are simplified; thus, reducing synthesis cost. In fact, these features of homogenous acidic catalysts render them advantageous over basic ones. With basic homogenous catalysts this; however, has not been possible due to the development of saponification reaction. To effectively perform, such catalysts require that the content of free fatty acids in the feedstock oil/fat is minimal. This requirement is also applicable to the moisture level in the feedstock. In terms of corrosive effects; nevertheless, acidic catalysts are disadvantageous compared to basic ones.
\end{abstract}

\section{Keywords: Homogenous; heterogeneous; acidic; basic; transesterification; saponification}

\subsection{Introduction}

Research on renewable biofuels has been prompted by a growing concern on exploitation, fluctuated high prices and exhaustion of classical fossil fuels for various energy-based-applications as well as by several environmental concerns. In fact, in order to exploit such fossil fuels, oil and gas in particular, complicated, costly and time-consuming drilling and processing are inevitable. Furthermore, in countries where such fossil fuels are imported, the concern can even be more higher where political tension can also be involved. From the environmental angle, such fuels are great environment pollutants through increased concentrations of greenhouse gas, i.e. $\mathrm{CO}_{2}$, they send during combustion promoting global warming. $98 \%$ of carbon emissions in the atmosphere are due to the combustion of these fossil fuels for different applications [1-2]. In addition to the emissions of $\mathrm{CO}_{2}$, such fuels do generate the emissions of particulate matter, sulfur, hydrocarbons, polycyclic aromatic hydrocarbons and nitrated polycyclic aromatic hydrocarbons. Of these emissions, the latter two ones have been identified as potential cancerous compounds [3].

Among biofuels family is biodiesel. Biodiesel is defined as a fuel, consists of a mixture of monoalkyl esters of long chain fatty acids (fatty acid methyl esters, FAME) derived from either vegetable oils or animal fats, that conforms to the requirements set by ASTM D6751 [4-5]. Biodiesel is a renewable, non-toxic, highly biodegradable fuel characterized with a unique features. Hence, it is apparent that hydrocarbons, aromatics and/or sulphur compounds, which are deemed as the main contributors to carbon and sulphur greenhouse gases into the atmosphere, are not among the contents of biodiesel as the case with petroleum diesel, although it has properties that are comparable to those of petroleum diesel. Accordingly, upon combustion, the environmental impact of use of biodiesel as a fuel can be milder in comparison to that of petroleum diesel. It has been reported that use of biodiesel in comparison to petroleum diesel introduces a reduction of emissions of particulate matter into the environment to nearly 77\% [6]. Promising results have also been reported elsewhere [7]. Also, Rashid, A., in his assessment of environmental hazards generated via using ordinary fossil fuels compared to biodiesel, has found that biodiesel produced the minimum amount of green house emissions, smoke, particulate matter and soot, poly-aromatic hydrocarbon emissions and odor [8]. In addition, the production of biodiesel offers some improved technological aspects as well as some social investments such as creation of new employments and rural revitalization. Consequently and also due to a growing public concern for a clean environment, biodiesel has been a topic of intensive research the world over indicating that rise in the synthesis and use of such a fuel are inevitable, although the cost of production of biofuels in general, including biodiesel, are still higher than that of the production of fossil fuels.

By far, synthesis of biodiesel relies on the transesterification of edible and non-edible vegetable oils. In fact, renewable readily available vegetable oils can be a prospective supply of energy that can replace those fossil fuels through synthesizing biodiesel out of them. Most influential factors affecting a transesterification reaction for biodiesel synthesis have been recently reviewed elsewhere [9]. As the case with most chemically synthesized products, common types of catalysts including, but not limiting to, acidic as well as basic homogenous catalysts have been examined for the purpose of synthesis of biodiesel. According to the available literature, this article has aimed to consider use of those homogenous catalysts, either acidic or basic, in the technology of biodiesel synthesis by means of transesterification reaction. In this article, due to their compatibility with several alcohols and their tolerance with different levels of free fatty acids contained in the parent feedstock oil/fat, acidic homogenous catalysts have grasped a much attention.

A representation of a general standard transesterification reaction is illustrated in Fig. (1). Transesterification is a chemical reaction that aims to lower the fat content of an oily feedstock via mixing with a certain alcohol; in most cases, in the presence of a certain catalyst type. Ideally, transesterification (alcoholysis) is a reversible equilibrium reaction, that can proceed to completion if one of its products (water) is removed from the reaction mixture through azerotropic distillation [10]; for instance, between triglyceride, which is extracted from the oil/fat used to produce biodiesel, and an excess of an alcohol, usually linear mono alcohols such as methanol or ethanol [11-12] although propyl, butyl/butanol and amyl alcohols are also used [13] with the advantage of a lower freezing points of the resultant biodiesel than that of the biodiesel obtained with the use of methanol as an alcohol [14-15]. Being a reversible reaction, transesterification usually involves use of an excess alcohol for a fast while complete triglyceride conversion [5,16]. Use of methanol in transesterification reactions has been reported in several investigations [10,17-25]. Methanol is preferred due to its low cost, in the United States, its cost is half as that of the cost of ethanol [26], physicochemical properties, e.g., polarity and smaller molecular size [10,19] and capability of swift reactivity being a short-chain alcohol [10,24-25]. Furthermore, separation and recovery of un-reacted methanol is simple [22].

While ethanol is preferred due to its availability and low toxicity to the environment since it is a renewable source entirely based on agriculture products having no dependence on classical petroleum. To this end; therefore, ethanol can be a first choice for the production of a wholly bio-generated biodiesel [11,27-30]. Moreover, due to the additional atom of carbon, compared to methanol, ethanol- based biodiesel is expected to slightly have a higher heat content and higher cetane number. Also, ethanol compared to methanol possesses a better dissolving capability of oils involved in transesterification reactions [31]. One further advantage of using ethanol instead of methanol as an alcohol in the transesterification reaction is an environmental one. In a study by Makareviciene, V. and Janulis, P., emissions of NOx, hydrocarbons, $\mathrm{CO}$ and $\mathrm{CO}_{2}$ and smoke density based on using rapeseed oil methyl ester (biodiesel), rapeseed oil ethyl ester (biodiesel) and fossil diesel were compared. Their results have indicated that rapeseed oil ethyl ester led to less negative effects on the environment in comparison with that of rapeseed oil methyl ester. In a water environment, they have also found that rapeseed oil ethyl ester was more swiftly biodegradable than rapeseed oil methyl ester. Furthermore, emissions generated while using rapeseed oil ethyl ester in comparison to fossil diesel were dropped as following: emissions of hydrocarbons were down by $53 \%$, $\mathrm{CO}$ emissions down by $7.2 \%$, $\mathrm{CO}_{2} \mathrm{emissions}$ down by $782.87 \mathrm{~g} / \mathrm{kWh}$ and smoke density down by $72.6 \%$ [32]. In terms of the physical and chemical properties as well as the performance of methyl esters and ethyl esters, they are generally comparable to each other. The heat content of both esters is similar although ethyl esters are with a higher viscosities while a lower cloud and pour points than that of methyl esters. In terms of the performance, engine tests indicated that methyl esters can produce a relatively higher power and torque than ethyl esters [33]. 
Nevertheless, use of ethanol as an alcohol in a transesterification reaction instead of methanol can give rise to some complications. In fact, obtaining a $100 \%$ chemical grade pure ethanol is a difficult task since it usually comes poisoned with some substances [34]. At the room temperature, both methanol and ethanol are immiscible with the triglycerides of the used vegetable oil. Hence, during a reaction, to promote mass transfer rates, mechanical agitation is usually applied to the reacting materials due which a stable emulsion may form. A methanol- based emulsion can demulsify spontaneously, leaving behind a lower glycerol-rich layer and an upper layer of methyl ester (biodiesel) that can be easily separated. However, an ethanol-based emulsion is a highly stable emulsion which may require the addition of demulsifier(s) in order to demulsify, i.e., a complication in biodiesel separation and purification [22]. Also, in a base-catalyzed transesterification reaction; in particular, rate of reaction is usually lower when ethanol is used rendering the formation of ethyl esters a difficult task. Such a difficulty is not encountered when methanol is used instead where methyl esters are easily formed [28,35-36]. Another issue associated with the use of ethanol as an alcohol instead of methanol in a transesterification reaction, which as pointed out earlier requires an excess of an alcohol, may arise during its recycle. In such a case, nearly double of what is required stoichiometrically of anhydrous ethanol is required. However recycled ethanol will not be anhydrous using a simple distillation procedure as the case if methanol was used. Another issue is that it is required to break the azeotrope, it forms with water [34], prior to ethanol reuse [28]. Moreover, use of ethanol instead of methanol can lead to the production of biodiesel that is more likely tend to lead to injector coking [33]. Despite this, Encinar and co-workers have advised that a suitable alcohol for a transesterification reaction is merely chosen with respect to its cost and performance considerations. They reported that although the kinetics of a transesterification reaction may differ with using a different alcohol, the ultimate ester's yield does not actually differ [29].

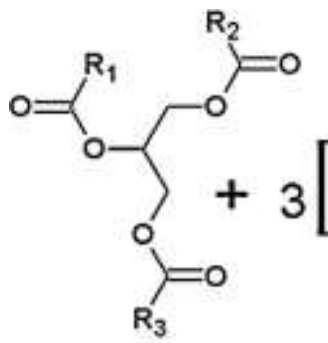

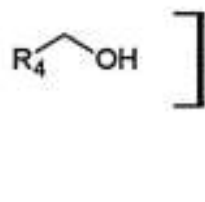

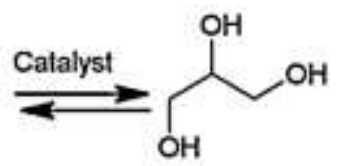

Alcohol<smiles>[R]OC([3H])=O</smiles>

Glycerol

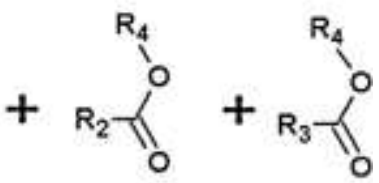

Fatty Acid Alkyl Esters (Biodiesel)

Figure 1: A Schematic Representation of a Standard Transesterification Reaction [37]

In order to achieve a sound conversion rate and a maximum yield in a shorter reaction time, transesterification reactions are catalyzed. A proper catalyst should perform as a miscibility enhancer of the reactants into the used alcohol. Depending on the content of free fatty acids contained within the parent vegetable crude oil/fat, a proper catalyst is chosen, provided that it can efficiently break triglycerides molecules into alkyl esters (biodiesel). Since transesterification is a reversible reaction, one further requirement of the chosen catalyst is that its amount should be adequate to catalyze both forward and backward reactions [38-39]. Generally, catalysts used for transesterification are either homogenous, heterogeneous or enzymatic. Homogenous catalysts used for the production of biodiesel are several and can be acidic or alkali/basic in nature [19,40]. Of these catalysts are: hydrochloric acid (HCl), sulfuric acid $\left(\mathrm{H}_{2} \mathrm{SO}_{4}\right)$, Lewis acids $\mathrm{BF}_{3}, \mathrm{TiCl}_{4}, \mathrm{HfCl}_{4}$.2tetrahydrofuran, Sc(OTf $)_{3}$, Phosphoric acid $\left(\mathrm{H}_{3} \mathrm{PO}_{4}\right)$, sulfonated organic acids $\left(\mathrm{RSO} \mathrm{H}_{3} \mathrm{H}\right)$; where $\mathrm{R}$ represents an organic combining group [41], sodium and potassium hydroxides ( $\mathrm{NaOH}$ and $\mathrm{KOH})$, sodium methoxide (NaOCH 3 ) [42-43], sodium ethoxide $\left(\mathrm{NaOCH}_{2} \mathrm{CH}_{3}\right)$ [42], sodium propoxide $\left(\mathrm{C}_{3} \mathrm{H}_{7} \mathrm{NaO}\right)$, sodium butoxide $\left(\mathrm{C}_{4} \mathrm{H}_{9} \mathrm{NaO}_{2}\right)$, carbonates [44] and solid resin $(\mathrm{Dowex}$ monosphere 550 A) [19,45]. Compared to potassium and sodium methoxides, potassium and sodium hydroxides are industrially advantageous due to their availability, low cost, ease of storage as well as transportation and chemical efficiency [29,46-48]. Chemically; however, both hydroxides and methoxides can be related to each other since their active species are methoxide ions [19]. According to the available literature, out of these catalysts, flakes of potassium and sodium hydroxides seem the mostly used ones. Several investigations have considered potassium hydroxide as a catalyst with which a biodiesel with good properties was produced [18,29,46,48-50, etc.]. Also, several investigations have considered sodium hydroxide as a catalyst with which a biodiesel with good properties was produced [22,27,51-53, etc.]. According to an investigation on the relationship between the yield of esters and time carried out by Encinar and co-workers, a potassium-based catalyst is better than a corresponding sodium-based catalyst [29]. Such catalysts are mainly used for small scale industrial applications. However, for larger continuous industrial applications, alkyl oxide solutions of a potassium/sodium methoxide in methanol, are; on the other hand, commercially desirable [54].

Combination of acid and alkali catalysts has also been reported [55-56]. Use of such catalysts; however, is usually associated with problems of: corrosion in equipment used, long reaction times, high cost [19], generation of large amounts of waste water effluents and low biodiesel yield due to some interactions between the used catalyst, alkali ones in particular [43], and the free fatty acids in case they are highly present in the feedstock oil (glycerides) [45,57-58]. A consequence of this interaction is the tendency towards the production of soap which has the sequence of reduction of the amount of available used catalyst meant for the transesterification reaction as well as catalyst deficiency. Furthermore, due to soap formation the viscosity increases while forming some gels by which ester yield decreases. Another consequence of this interaction is some complications and increased cost in the downstream separation for the purpose of biodiesel purification $[19,43]$.

Heterogeneous solid acidic and basic catalysts such as: metal oxides, metal complexes, membranes, lipases [59], amberlyst-15 [60], active metals loaded on supports, SBA-15 impregnated with cesium [61], zeolites [59,62], La/zeolite beta [63] and resins [59], etc., have also been tested for the production of biodiesel. Industrially, heterogeneous solid catalysts in comparison to homogenous catalysts are preferred due to reusability and regeneration, ease of separation and minimum waste [5]. Nevertheless, low activity, the need of use of a solvent, long reaction time, high cost and high temperature are all possible problems that may be encountered while using heterogeneous solid catalysts [58]. Low activity and; thus, long reaction times are due the fact that active sites of a heterogeneous solid catalysts are restricted only to its surface by which the reaction becomes somewhat limited under the influence of internal mass transfer resistance [5]. It is beyond the scope of this article to further discuss such heterogeneous solid catalysts.

To this end, only use of homogenous acidic and basic catalysts in biodiesel synthesis is further considered in this article in two separate consecutive sections. In terms of reaction mechanism, each type of these homogenous catalysts acts differently throughout a transesterification reaction regardless of the nature of the feedstock used. Considering the catalyst-substrate interactions (catalyst activity), the chemical pathways of an acid-catalyzed transesterification reaction show that the key step in the reaction is the protonation of the carbonyl oxygen by which its vulnerability to nucleophilic attack increases as a result of increased electrophilicity of the adjacent carbon atom, refer to Fig.(2). Where as in case a base catalyst has been used instead, a different chemical reaction pathway can be observed in which a more direct route can be identified. An alkoxide ion is created, acting directly as a strong nucleophile, as indicated in Fig.(3). 
(1)<smiles>[R]C(=O)OCC(COC([R])=O)OC(COC([R])=O)COC(C)=O</smiles>

(2)

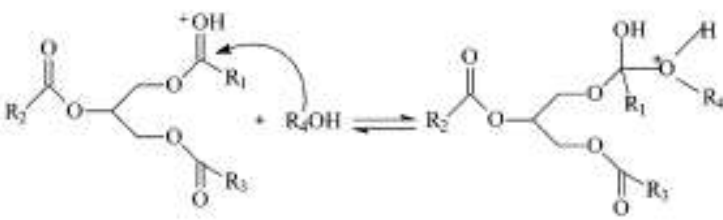

(3)

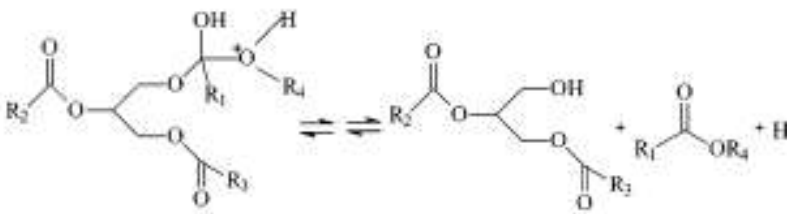

$\mathbb{R}_{1}, \mathbb{R}_{2}, \mathbb{R}_{3}:$ carton chuin of $t w e$ fiety acids $R_{4}$; allikyl group of the aksohol

Figure 2: Homogenous Acidic-Catalyzed Reaction Mechanism for Transesterification [19].

(2)

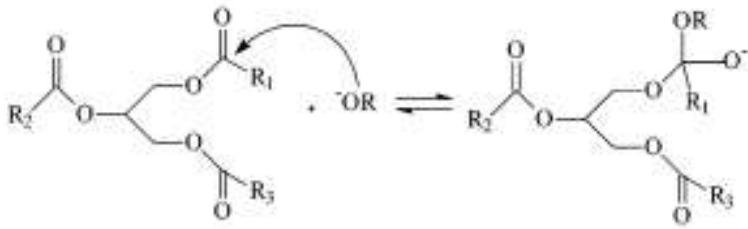

(3)

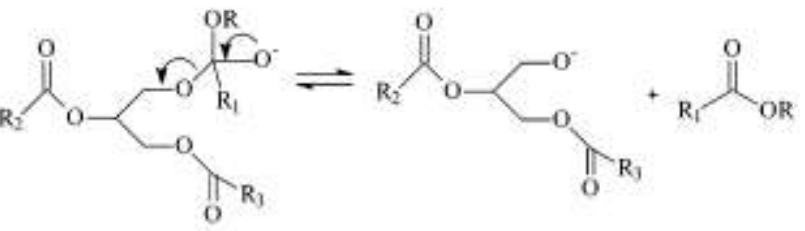

(4)<smiles>[R]C(=O)OCC(C[O-])OC([R3])=O</smiles>

\author{
B: base catalyst \\ $R_{1}, R_{2}, R_{3}$ : carbon ctain of the fatty acids
}

R: akyl group of the alcolol

Figure 3: Homogenous Basic-Catalyzed Reaction Mechanism for Transesterification [19]

\title{
2.0. Homogenous Acidic Catalysts in Biodiesel Synthesis
}

In general, the catalytic activity of homogenous catalysts is proven since the active sites are within a liquid phase and are capable to move freely in the reagents [5]. In commercial applications for the purpose of biodiesel production, acid-catalyzed homogenous transesterification reactions in comparison to base-catalyzed homogenous transesterification reactions have not been very popular in spite of their insensitivity to high contents of free fatty acids in the feedstock oil. One reason for such a trend is the fast rate of the latter reactions, nearly 4000 times higher, than that of the former ones [12,16,21,41,64-69]. Another reason can be due to their stronger corrosive nature than liquid base catalysts [5]. Also, in terms of alcohol purity, acidcatalyzed transesterification reactions require alcohols of high concentrations for a high and fast conversion. Furthermore, in order to achieve a certain yield, acid-catalyzed transesterification of waste vegetable oils, which usually contain a high content of free fatty acids, usually requires very high alcohol to oil molar ratios compared to a base-catalyzed transesterification [68,70]. In addition, in acid-catalyzed transesterification reactions, high reaction temperatures are a must to attain a fast reaction rate [19] through improved miscibility of the alcoholic polar medium into a non-polar oily phase [5] Such an observation was also reported by Schwab and co-workers and Liu, K. [65-66]. On the contrary; however, base-catalyzed transesterification reactions generally require lower temperatures and pressures. Also, they can provide biodiesel yields of up to $98 \%$ requiring no intermediate compound(s) for a direct conversion into biodiesel nor a special material(s) of construction of process equipment [54]. Although with using either an acidic or a base catalyst in the transetserification of a feedstock with a high free fatty acids content such as greases and oil wastes, considerable amount of water can be generated out from the transetserification reaction, an acidic catalyst; however, is commonly thought to be more accommodative of a high content of free fatty acids in the parent feedstock [12,66,71]. This water is with a negative effect on the production of biodiesel as it can hydrolyze the produced ester producing free fatty acids again [19,21,72-74]. It also can lead to a reduced reaction rate and to a reversible type of catalyst deactivation Such a phenomenon of catalyst deactivation was explained through the strong affinity between an acidic catalyst and water in a study by Sridharan, R. and Mathai, I. M., for which the reader is directed to for further chemistry details [74]. Besides, acid-catalyzed transesterification suffers from a production of acidic effluent, no reusability of the catalyst leading to severe separation problems as well as high cost of required equipment [70].

In contrast, in an acid-catalyzed homogenous transesterification reaction, the catalyst can be advantageous over a base-catalyzed homogenous transesterification reaction catalyst. In acid-catalyzed transesterification, a variety of alcohols can be used including methanol, ethanol, propanol, butanol as well as amyl alcohol [19]. This feature broadens the applicability of acidic catalysts for transesterification reactions. Also, in order to reduce the content of free fatty acids in the parent feedstock vegetable oil employed for biodiesel synthesis, an esterification reaction prior to the transesterification 
reaction is usually required. Out of an esterification reaction, water is formed. This water if allowed to accumulate could stop the transesterification reaction. Thus, it should be removed at the end of esterification reaction [75]. To catalyze this esterification reaction, sulfuric acid is typically used due to its low cost [76-77]. Such a procedure was exactly followed to obtain biodiesel from palm oil of a high content of free fatty acids in a study performed by Gabriel and co-workers. They firstly carried out an acid-catalyzed esterification reaction using sulphuric acid to reduce the acidity of palm oil and then carried out the transesterification reaction using a base catalyst, $\mathrm{KOH}$. The procedure adopted in this study was successful and allowed to obtain biodiesel that meets the specifications described in the European standards [78].

It has been reported that in order for a base catalyst to perform effectively in biodiesel production and that produced biodiesel is within the ASTM standards, the amount of free fatty acids in the employed feedstock ought to be lower than or equal to $0.5 \%$ [79]. This advantage renders acidic catalysts a suitable candidate for integrated pre-esterification and transesterification processes of such feedstocks where the content of free fatty acids is high [19]. In the literature, it has been emphasized that acid catalysts are more efficient than alkaline/base catalysts in transesterifying a vegetable oil with more than $1 \%$ free fatty acid $[66,71]$. Ultimately, this has the potential to lower the cost of biodiesel production since such feedstocks are non-edible oil sources or classified as a waste. Furthermore, if an acid catalyst(s), instead of a basic catalyst(s), are to be employed to catalyze a transesterification reaction, several drawbacks can be circumvented, e.g., intensive energy consumption due to tricky recovery of glycerol (a byproduct of transesterification reaction), removal of the catalyst from the produced biodiesel and the required treatment of the resultant basic waste water [80]. Another advantage of homogenous acidic catalysts is that they demonstrate no sensitivity to a wide range of feedstocks of biodiesel synthesis as would be demonstrated later. Also, reusability and recoverability of homogenous acidic catalysts can also be ensured [5].

Also, in order to conquer the most catastrophic issues such as slow reaction rates and saponification (an undesirable side reaction induced via the presence of water and/or free fatty acids in the raw vegetable oil feedstock which spontaneously result in the development of soap [5]), that are usually encountered in a base-catalyzed transesterification of waste oils in particular where the content of free fatty acids is inevitably high, when they are employed separately for biodiesel production, a two-step transesterification process was proposed. In order to reduce the level of free fatty acids originally contained in the waste oil to levels that do not give rise to saponification, $<1 \%$, when a base catalyst is later used, according to such a procedure, free fatty acids contained in the waste oil are firstly esterified using an acid catalyst. In the second step, transesterification of this esterified waste oil is carried out using a base catalyst. Hancsok and co-workers have used this two-step scheme of transesterification in the transesterification of a used frying oil, with a free fatty acids content of $32.5 \%$, in methanol using sulfuric acid and sodium methylate as catalysts in the first and second steps; respectively. As additives, they used tetrahydrofuran and dioxine as co-solvents separately. The conditions of the first step were as following: 4:1 as a molar ratio of methanol and tetrahydrofuran to oil, $15 \%$ concentration of sulfuric acid and a temperature of $60{ }^{\circ} \mathrm{C}$ for 0.5 to 6 hours. Similarly, the conditions of the second step were as following: $4: 1$ as a molar ratio of methanol and tetrahydrofuran to oil, a temperature of $60{ }^{\circ} \mathrm{C}$ although the concentration of the base catalyst used, sodium methylate, was $3 \%$ and running the reaction for 2 hours only. They found that addition of co-solvents reduced the content of free fatty acids of the transesterified frying oil; thus, shortening the required time during the first step. Following the second step, an ester yield of $96.5 \%$ was achieved [81].

Wang and co-workers have compared the classical acid-catalyzed transesterification of waste cooking oil, in methanol as an alcohol, with a two-step transesterification scheme using methanol again. In the classical acid-catalyzed transesterification, they used an acidic catalyst, sulfuric acid, where as in the two-step transesterification scheme, they used an acidic catalyst, ferric sulfate (2.0\%), in the first step followed by the use of a base catalyst, $1.0 \%$ potassium hydroxide, in the second step. In both scenarios, a high temperature of $95{ }^{\circ} \mathrm{C}$ was applied. They found that the yield of methyl esters out of the two-step scheme is higher than that obtained out of a classical acid-catalyzed transesterification. It was $97.22 \%$ in the two-step scheme compared to only $90 \%$ in the classical acid-catalyzed transesterification. Required time of reaction; however, was; otherwise. It was lower in the two-step scheme, of only 4 hours compared to 10 hours in the other process. This was also the case in terms of the molar ratio of methanol to oil. It was 10:1 in the two-step scheme compared to 20:1 in the classical acid-catalyzed transesterification. In addition to these sound achievements, this two-step scheme led to other advantages including: low cost of the used equipment, generation of no acidic wastewater and ease of recovery of the used catalyst [70]. Also, Issariyakul and co-workers have compared the classical base-catalyzed transesterification of waste fryer grease containing between 5 and 6 wt.\% free fatty acids with a two-step transesterification scheme. They obtained higher than $90 \%$ ester yield out of the two-step transesterification scheme in comparison to only $50 \%$ out of the classical base-catalyzed transesterification [82].

Comparable results were also obtained via the two-step transesterification scheme of a waste frying oil by Encinar and co-workers [29]. Promising results were also reported by Cayli, G. and Küsefoglu, S., and Wan Omar and co-workers in their work of a two-step base-catalyzed transesterification scheme at room temperature of used cooking oil in methanol [83-84]. Furthermore, Ghadge, S. V. and Raheman, H. have employed an acidic catalyst, 1\% $\mathrm{v} / \mathrm{v} \mathrm{H}_{2} \mathrm{SO}_{4}$, to esterify a crude mahua non-edible oil using methanol. A remarkable reduction in the content of free fatty acids contained in the crude mahua non-edible oil was achieved. They were able to reduce the content of free fatty acids from 19 wt.\% down to only 1 wt.\% ready for transesterification for biodiesel production [85]. Likewise, Veljković and co-workers reduced the content of free fatty acids contained in tobacco seed oil from $17 \mathrm{wt.} \%$ down to only $2 \mathrm{wt. \%}$ [86]. A similar work was also carried out by Sahoo and others as well as Hayyan and others [87-88].

Nevertheless, in the two-step transesterification scheme, the problem of catalyst removal from the reaction medium in the first and second steps by neutralization and use of a more base catalyst; respectively, entails additional cost, cost of extra catalyst, to the cost of biodiesel production [31].

In addition, to catalyze esterification reactions, liquid Bronsted acid homogenous catalysts such as hydrochloric acid, phosphoric acid and sulfuric acid, etc., have been powerfully used. Among these liquid Bronsted acid catalysts, sulfuric acid is the most effective one. Khan, A. in a research work into biodiesel kinetics and catalyst development has found that using $1.7 \mathrm{wt} . \%$ sulfuric acid at $240{ }^{\circ} \mathrm{C}$ and 70 bar in the esterification of crude tallow and used oils over several different catalysts, sulfuric acid achieved a remarkably high catalytic activity ( $90 \%$ acid conversion) in no more than 15 minutes, as a time of reaction [89]. However, side reactions, e.g., alcohol dehydration, were inevitable under such harsh conditions [5]. Liquid Lewis acid homogenous catalysts which include: $\mathrm{BF}_{3}, \mathrm{TiCl}_{4}, \mathrm{HfCl}_{4}$ and $\mathrm{Sc}(\mathrm{OTf})_{3}$, etc., have also been used. In terms of side reactions that might develop while using liquid Lewis acid catalysts compared to liquid Bronsted acid catalysts, they can be controllable. With using liquid Lewis acid catalysts, undesired side reactions, e.g., alcohol dehydration can be suppressed [90-93]. Water formed whether from the direct esterification reaction or from alcohol dehydration side reaction possesses a negative impact on the reaction rate due to thermodynamic limitations and lowering the catalyst performance by strongly binding to the active species $\left(\mathrm{H}^{+}\right)$in the solution, producing a weaker acid [5].

Their capability to catalyze a single transesterification reaction by which a biodiesel is synthesized, homogenous acidic catalysts have also been scrutinized. Al-Widyan MI and Al-Shyoukh AO, in their investigation of conversion of used palm oil to diesel fuel (ethyl esters) by transesterification, have compared the performance of $\mathrm{HCl}$ and $\mathrm{H}_{2} \mathrm{SO}_{4}$ as an acidic catalysts. They have found that as the concentration of the used catalyst is increased between $1.5 \mathrm{M}$ and $2.25 \mathrm{M}$, produced biodiesel/ethyl esters can be obtained in a shorter reaction time and having a lower specific gravity, i.e., more heavy glycerine is removed; thus, better driving the reaction towards the completion. At the highest catalyst concentration tested, $2.25 \mathrm{M}_{2} \mathrm{H}_{2} \mathrm{SO}_{4}$ acid was superior to $\mathrm{HCl}$ acid in terms of conversion levels. The best process combination was $2.25 \mathrm{M} \mathrm{H}_{2} \mathrm{SO}_{4}$ with $100 \%$ excess ethanol which reduced the specific gravity from an initial value of 0.916 to a final value of 0.8737 in about 3 hours of reaction time. Biodiesel produced had the behavior of a Newtonian fluid [94]. Nye and others, in their investigation of conversion of used frying oil to biodiesel fuel (methyl esters) by transesterification, have compared the performance of acidic and basic catalysts. They have found that an acidic catalyst gave $81 \%$ conversion of 1-butyl ester at $25 \mathrm{C}^{\circ}$ and a conversion of $72 \%$ of ethyl ester. A base catalyst; however, gave $74 \%$ conversion of methyl ester (biodiesel). They have successfully demonstrated the possibility of the conversion of a waste used frying oil to biodiesel (methyl esters) through transesterification [95]. Similarly, the production of biodiesel from waste frying oils has been investigated by Predojević, Z. J. A biodiesel yield of $92 \%$ was obtained [96]. A.Banerjee and R.Chakraborty have also studied the acidcatalyzed transesterification of waste cooking oil for the purpose of biodiesel production using methanol as an alcohol. In this study, good results were 
also obtained. They have obtained a high biodiesel yield of 98.9\% [97]. In addition to the use of acid-catalyzed transesterification for the variety of feedstocks just mentioned, it also has been used in the transesterification of heterotrophic microalgal oil and microalgae Chlorella pyrenoidosa. In both investigations, sulfuric acid was used and a somewhat high biodiesel yield was achieved [98-99].

Moreover, acid-catalyzed transesterification of crude edible vegetable oils has been in use. M. Canakci, J and Van Gerpen in their work of production of biodiesel via acid catalyst, sulfuric acid, have investigated the effect of several factors on the yield of acid catalyst, sulfuric acid with different amounts, $1 \%, 3 \%$ and $5 \%$, using soybean oil as a vegetable oil and methanol as an alcohol. They considered the effect of: molar ratio, reaction temperature, reaction time, catalyst amount, alcohol type, water and free fatty acids on the yield of acid-catalyzed methyl ester. They selected five different molar ratios, 3.3:1, $3.9: 1,6: 1,20: 1$ and 30:1, while maintained the concentration of the sulfuric acid at $3 \%$, reaction temperature at $60^{\circ} \mathrm{C}$ and running the reaction for consecutive 48 hours ( 2880 minutes). They found that the higher the molar ratio, the higher the ester conversion reaching $98.4 \%$ with a molar ratio of 30:1. However, they noticed that the specific gravity of the produced ester decreased with increasing the molar ratio, perhaps due to a decrease in residual triglycerides [76]. Comparable results have also been reported elsewhere [100-101]. In addition, in an investigation carried out by Freedman, et al. on a mixture of soybean oil with butanol with using sulfuric acid as a catalyst, kinetics of transesterification reaction were examined. During the reaction, rate-limiting step was found to be varying with time with three regimes that can be identified. In the first regime; the onset of the reaction, due to low miscibility of both the catalyst and used reagents due to a difference in their polarities, the reaction was controlled by mass-transfer. Later, kinetics commenced to control the reaction as it went on where esters (products) were increasingly developed. Emulsification characteristics of developed esters were crucial for this regime. The last regime represented the equilibrium stage and was reached towards the completion of the reaction. The forward reactions demonstrated a pseudo-first order kinetics where as the reverse reactions followed a second order kinetics. This investigation also suggested that the high molar ratio of alcohol-to-oil as 30:1 was just sufficient for an acceptable reaction rate [64].

Regarding the effect of temperature on the performance of an acid-catalyzed transesterification reaction, M. Canakci, J and Van Gerpen have observed that ester conversion increased almost linearly with increasing reaction temperature between $25^{\circ} \mathrm{C}$ and $60^{\circ} \mathrm{C}$. The highest reaction temperature, $60^{\circ} \mathrm{C}$, was selected to avoid surpassing the boiling point of the used alcohol (methanol), $65^{\circ} \mathrm{C}$. Ester conversions were $8.3 \%, 57.2 \%$ and $87.8 \%$ at $25^{\circ} \mathrm{C}, 45^{\circ} \mathrm{C}$ and $60^{\circ} \mathrm{C}$, respectively. The specific gravity of the ester; however, decreased with increasing reaction temperature. The maximum specific gravity of the methyl ester (biodiesel) was 0.917 , which is close to the specific gravity of the used vegetable oil, soybean oil. Similarly, longer reaction durations were found to have a good effect on ester conversion. Ester conversion increased from $87.8 \%$ to $95.1 \%$ with doubling reaction time from 48 hours to 96 hours. Furthermore, ester formation increased from $72.7 \%$ to $95.0 \%$ as the concentration of the catalyst was increased from $1 \%$ to $5 \%$. Although it is reported in the literature that an alcohol with a longer chain demonstrates a higher ester conversion than that obtained using an alcohol with a shorter chain, this investigation has; however, revealed a slightly dissimilar trend. The performance of: methanol, ethanol, 2-propanol and 1-butanol in the transesterification reaction was examined. Surprisingly, they found that the highest ester conversion occurred with ethanol followed by that obtained with 2-propanol followed by that obtained with 1-butanol and expectedly by that obtained with methanol. No justification was expressed for this discrepancy in their investigation. Finally, in this study by M. Canakci, J and Van Gerpen, the effect of water and free fatty acids on the yield of acidcatalyzed methyl ester (biodiesel) was also examined. They observed that presence of water even in a trivial amount of $0.1 \mathrm{w} \%$ in the vegetable oil reduces the ester yield. Presence of more water further reduces the ester yield. A $5 \mathrm{w} \%$ water in the vegetable oil significantly reduced the ester yield down to $5.6 \%$ compared to that obtained with no water, $95.1 \%$. Also, this investigation has investigated the effect of presence of free fatty acids in the used vegetable oil, soybean, on ester conversion. Due to availability and low cost, palmitic acid was used to model free fatty acids. Concentrations of palmitic acid tested were: $5 \%, 10 \%, 15 \%, 20 \%$ and $33 \%$. It was found that the conversion rate of soybean oil to methyl ester (biodiesel) dropped below $90 \%$ for concentrations of free fatty acids higher than $5 \%$. Free fatty acids contained in the used vegetable oil reacted with the used alcohol. Among the products of such reaction is water. As explained earlier, presence of water within the transesterification reaction medium strongly hampers ester conversion [76].

\subsection{Homogenous Basic Catalysts in Biodiesel Synthesis}

Alkali/base homogenous catalysts for transesterification reactions have been extensively investigated. Freedman and others have reported that for a maximum ester yield, the used alcohol as well as the used vegetable oil have to be free of moisture and that the acid value is lower than $1 \mathrm{mg} \mathrm{KOH/g} \mathrm{[71]}$ Nye and Southwell have found that at the room temperature, hydroxides and alkoxides were of good use in the transesterification of rapeseed oil to methyl and ethyl esters [102]. Sodium hydroxide as a catalyst was also used in a study carried out by Fan and co-workers. Their results indicated that a yield of $97 \%$ of biodiesel was obtained provided that methanol/oil molar ratio is $7.9: 1$, catalyst concentration is $1.0 \%$, temperature is $53^{\circ} \mathrm{C}$, rate of mixing is $268 \mathrm{rpm}$ and that reaction duration is for $45 \mathrm{~min}$ [103]. In another two earlier studies, a high yield of more than $95 \%$ of fatty esters in one hour's reaction time was obtained using either sodium ethoxide, sodium hydroxide or sodium methoxide with methanol, ethanol or 1-butanol as alcohols, in the transesterification of sunflower and soybean oils, respectively [101,104]. Also, Canoira with others have used jojoba oil-wax for the purpose of biodiesel production through transesterification with methanol catalyzed with sodium methoxide $1 \mathrm{wt} \%$. They attained a biodiesel yield of $79 \mathrm{wt} \%$ with a molar ratio of 7.5:1 and at a temperature of $60^{\circ} \mathrm{C}$, although for a quite lengthy reaction, for $240 \mathrm{~min}$ [105]. Theoretically, Jeong with others have reported that comparable results were also predicted by use of a statistical optimization model. Biodiesel yield was 98.6\%, molar ratio was 7.5:1 and temperature was $65^{\circ} \mathrm{C}$. However, the predicted reaction time was only $20 \mathrm{~min}[106]$

Furthermore, Boocock and co-workers have reported that addition of several simple ethers such as: tetrahydrofuran, 1,4-dioxane, diethyl ether diisopropyl ether and tert-butyl methyl ether to the solution of the alkali catalyst used (1.3\% sodium hydroxide) and methyl alcohol is an efficient method for accelerating the transesterification reaction. Addition of tetrahydrofuran in particular to the used catalyst (1.3\% sodium hydroxide) to methyl alcohol in the transesterification of soybean oil gave $95 \%$ methyl ester (biodiesel) in only 15 min [107]. Comparable work and results were also reported by Soriano and co-workers [68]. In another work by Phan, A., N. and Phan, T. M., use of $0.75 \mathrm{wt. \%}$ potassium hydroxide (KOH) as an alkali/base catalyst for transesterification of a waste cooking oil with methanol has been investigated. They changed the reaction temperature from $30{ }^{\circ} \mathrm{C}$ to $50{ }^{\circ} \mathrm{C}$ and methanol/oil molar ratio from 5:1 to 12:1. In all experiments, the duration of the reaction was for $80 \mathrm{~min}$. Accordingly, they obtained a yield of biodiesel between $88 \%$ and $90 \%$ at a molar ratio of 8:1. With a higher molar ratios, i.e., more excess methanol, the yield decreased. This is due to the interference of methanol with alkyl ester and glycerol which ultimately leads to foam formation [108]. In another work, Rao and co-workers obtained biodiesel using an alkali catalyst, $\mathrm{KOH}$, via the transesterification of used sunflower oil containing a low free fatty acids content with methanol. In the paper, it was mentioned that the parameters of the transesterification reaction were experimentally optimized although no details were given [109]. Also, using another crop, Haile and co-workers have investigated the production of biodiesel from waste coffee grounds obviously due to their wide availability where they conducted the work and due to their high antioxidant character [110-111]. In doing so, they prepared the biodiesel in two consecutive steps. In the first step, esterification, they used the sulphuric acid as an acidic catalyst. However, a base catalyst, sodium hydroxide, was used in the second step, transesterification. They reported a reasonable conversion of waste coffee grounds into biodiesel, $73.4 \mathrm{w} / \mathrm{w} \%$. Obtained biodiesel was of standards complying with ASTM D 6751- 09. Such a produced biodiesel via the available crops of waste coffee grounds can supplement the energy sector by 10.32 million gallons per year [112]. A similar work concerning the transesterification of palm oil with methanol in the presence of $\mathrm{KOH}$ as a catalyst was also reported by Darnoko, D. and Cheryan, M. [113].

Optimized results were also reported by Rashid, et al. via their work of transesterification of sunflower vegetable oil via an alkali-catalyst, sodium hydroxide $(\mathrm{NaOH})$ with methanol. Their results stated that with optimum reaction conditions of: methanol to oil molar ratio 6:1, catalyst concentration 1 $\mathrm{w} / \mathrm{w} \%$ and reaction temperature $60{ }^{\circ} \mathrm{C}$, optimum biodiesel yield of $97.1 \%$ can be obtained [114]. Comparable results were also reported by Encinar and co-workers [29]. The catalytic activity of two alkali catalysts, $\mathrm{KOH}$ and $\mathrm{NaOH}$, in the transesterification of a waste cooking oil with a content of free fatty acids of 2.76 was compared by Dorado and co-workers. It was concluded that while using the first catalyst, the transesterification reaction proceeded faster than when the second catalyst was used [47]. 
In fact, base catalysts are only effective in the transesterification of highly refined vegetable oils [115]. Acid catalysts are relatively low in cost with high production yields [5]. The performance of an acidic catalyst relative to a base catalyst only somewhat collapses by the high content of free fatty acids contained in the feedstock as the case with waste greases/oils and animal fats. In fact, use of a base catalyst for such feedstocks that have a high water content gives a rise to the hydrolysis reaction due to which biodiesel yield declines [115]. Also, use of a base catalyst for such feedstocks that are rich with free fatty acids is rather problematic and can be associated with no conversion of such free fatty acids and a saponification reaction between the base catalyst and those free fatty acids creating negative impacts in terms of biodiesel purification and production cost [76,115-118]. Once produced, soap can create a stable emulsion which is classified as a waste water and renders purification of biodiesel and separation of the used catalyst a challenging task due to increased viscosity. As a remedy, a pretreatment process prior to the transesterification step, an esterification reaction using an acidic catalyst, usually sulfuric acid, with an alcohol in which the level of free fatty acids of the parent oil or fat is reduced following partially converting them into methy esters and glycerides [26] to no more than $0.5 \mathrm{wt} . \%$ [119], of such a feedstock may be required, although at an additional cost. It should be clearly observed that use of sulfuric acid or any other homogenous catalyst in such a reaction results in an added neutralization and separation procedures.

\subsection{Summary}

Having discussed the peculiarity and performance of both homogenous acidic and basic catalysts in transesterification reactions of several feedstocks under different reaction conditions, they can by no means considered perfect. To perform well, acid catalysts, which are naturally corrosive, usually require high temperatures while longer reaction durations $[19,26]$ due to inevitable use of higher alcohol to oil molar ratios. Furthermore, to obtain a satisfactory yield, use of base catalysts requires the use of highly expensive refined oils or fats as a primary feedstock. Base catalysts are unfortunately also quite sensitive to water and free fatty acids present in the transesterified feedstock. Technically, removal of such catalysts from the alcohol/glycerol phase is a difficult costly task [26]. Also, when either catalyst is used, glycerol recovery is an issue [26]. Both acidic and basic catalyzed-transesterification reactions are of a great concern to the environment for generating a considerable amount of wastewater since huge amount of water is required for catalyst-product separation [115]. Of- course, the cost of biodiesel production can be increased as a consequence of this. A summary of various applications of acidic and basic homogenous catalysts in biodiesel synthesis along with their main pros and cons is synopsized in Table (1).

Table 1: A Summary of Uses, Advantages and Disadvantageous of Acidic and Basic Catalysts for Transesterification Reaction

\begin{tabular}{|c|c|c|}
\hline $\begin{array}{l}\text { Homogenous } \\
\text { Catalyst Type }\end{array}$ & Acidic Catalysts & Basic Catalysts \\
\hline Application(s) & $\begin{array}{l}\text { - They are used only in case the concentration of free fatty } \\
\text { acids within the vegetable oil/animal fat is high [13]. }\end{array}$ & $\begin{array}{l}\text { - To avoid saponification: They are used only in case the } \\
\text { vegetable/animal oil is water-free [30]. Also, they are used } \\
\text { only in case the concentration of free fatty acids within the } \\
\text { vegetable/animal oil is low, less than } 0.5 \mathrm{wt} . \%[19,30] \text {. } \\
\text { - They require some pretreatment [13]. They must be } \\
\text { anhydrous (total water content must be } 0.1-0.3 \mathrm{wt} \% \text { or } \\
\text { less). The used alcohol must be anhydrous (total water } \\
\text { content must be } 0.1-0.3 \text { wt } \% \text { or less) [19]. } \\
\text { - To be in line with such specifications, the used vegetable } \\
\text { oil source must be highly refined [19]. }\end{array}$ \\
\hline Advantages & $\begin{array}{l}\text { - Compatibility with various alcohols. } \\
\text { - Suitability with a broad range of content of feedstocks of } \\
\text { different free fatty acids. }\end{array}$ & $\begin{array}{l}\text { - Nearly, } 4000 \text { times faster than acidic catalysts [30]. } \\
\text { - Do not require a large quantity of alcohol relative to } \\
\text { vegetable oil/animal fat. A molar ratio of alcohol: oil of 6:1 } \\
\text { is usually accepted [13]. }\end{array}$ \\
\hline Disadvantages & $\begin{array}{l}\text { - To attain a satisfactory biodiesel yield, large quantities of } \\
\text { alcohol relative to vegetable/animal oil are required. A } \\
\text { molar ratio of alcohol: oil of } 30-150: 1 \text { is usually required. } \\
\text { - Slow transesterification reactions. Hence: } \\
\text { - Long reaction times up to } 48-96 \mathrm{hrs} \text { [120]. Also, risk of } \\
\text { corrosion of equipment due to high levels of acidity [13]. }\end{array}$ & $\begin{array}{l}\text {-Time-consuming. } \\
\text { - Costly [19]. } \\
\text { - Inevitable generation of undesirable water (waste) } \\
\text { during reaction of hydroxide ion with the used alcohol. } \\
\text { - Saponification. } \\
\text { - Technical difficulty in catalyst separation [120]. }\end{array}$ \\
\hline
\end{tabular}

\subsection{Conclusion}

Although several alcohols are available for transesterification reaction in biodiesel synthesis, care should be paid while deciding the suitable alcohol. Low reactivity, generation of waste due to use of solvents, harsh reaction conditions as well as high cost can be avoided if a homogenous catalyst is used instead of a heterogamous one. It has also been observed that a considerable cost reduction in the synthesis of biodiesel can be achieved if cheap while widely available waste feedstocks, that are indigenously accompanied with a high level of free fatty acids, are employed instead of expensive edible feedstocks. This; however, renders use of a homogenous acidic catalyst, instead of a homogenous basic catalyst, a first option to avoid saponification reaction. With such an option, non-metallic equipment should be used to avoid corrosion effects. During transesterification reactions, temperature is with a positive influence on ester conversion while using a homogenous acidic catalyst. Literature cited has demonstrated that out of the considered several feedstocks, which are with different levels of free fatty acids, biodiesel of acceptable specifications has been synthesized with the help of a homogenous acidic and/or basic catalyst. Details of cited works reveal that the yield of biodiesel is worthwhile.

\section{References}

[1] E., G. Shay, "Diesel fuel from vegetable oils: status and opportunities”. Biomass and Bioenergy, Vol. 4, Pp. 227-242, 1993.

[2] E. F, Aransiola, E. Betiku, D.I.O., Ikhuomoregbe, T.V. Ojumu. "Production of biodiesel from crude neem oil feedstock and its emissions from intern Aransiola al combustion engines”. African Journal of Biotechnology, Vol. 11, No. 22, Pp. 6178-6186. 2012.

[3] S. Howell, and J. Jobe, "Current Status of the Biodiesel Industry. Chapter Eight. In The Biodiesel Handbook (Ed.) Gerhard Knothe, Jon Van Gerpen and Jürgen Krahl. Champaign, Illinois". Copyright (c) 2005 AOCS Press.

[4] G. Knothe, J.V. Gerpen and J Krahl. "Oxidative Stability of Biodiesel. Chapter Six. In The Biodiesel Handbook (Ed.) Champaign, Illinois”. Copyright @ 2005 AOCS Press.

[5] K Suwannakarn. "Biodiesel Production From High Free Fatty Acid Content Feedstocks. PhD thesis, University of Clemson University". Tiger Prints 2008.

[6] G. Knothe., C. A. Sharp., T. W. Ryan. "Exhaust Emissions of Biodiesel, Petrodiesel, Neat Methyl Esters, and Alkanes in a New Technology Engine". Energy \& Fuels, Vol. 20, Pp. 403- 408. 2006.

[7] L. Rubianto., S. S. Yuwono., A. Soemarno. "Comparison of Biodiesel and Petrodiesel Particulate Emission". The International Journal of Engineering and Science, Vol. 2, Pp. 66-69. 2013.

[8] R. Ali. "Biodiesel a renewable alternate clean and environment friendly fuel for petrodiesel engines: A review" International Journal of Engineering Science and Technology (IJEST), Vol. 3 No. 10, Pp. 7707-7713, ISSN 0975-5462. 2011. 
[9] A., M. Shakorfow, and A., H. Mohamed, "Influential Parameters Affecting Transesterification Reaction in Biodiesel Synthesis: A Review". The International Journal of Engineering and Information Technology (IJEIT), Vol.6, No.2, Pp. 151-157, 2020.

[10] F. Ma and M. A. Hanna, "Biodiesel production: a review". Bioresource Technology, Vol. 70, pp. 1-15, ISSN 0960-8524. 1999.

[11] A. Demirbas, "Biodiesel fuels from vegetable oils via catalytic and noncatalytic supercritical alcohol transesterifications and other methods: a survey". Energy Convers. Manage. Vol. 44, Pp. 2093-2109, 2003a.

[12] H. Fukuda; A. Kondo; H. Noda, “Biodiesel fuel production by transesterification of oils”. J. Biosci. Bioeng. Vol. 92, Pp. 405- 416, 2001.

[13] L. Andreani and J. D. Rocha. "Use of Ionic Liquids In Biodiesel Production: A Review”. Brazilian Journal of Chemical Engineering. Vol. 29, No. 01, Pp. 1 - 13, January - March, ISSN 0104-6632. 2012.

[14] I., Lee, L.A. Johnson, and E.G. Hammond, "Use of Branched-Chain Esters to Reduce the Crystallization Temperature of Biodiesel”, J. Am. Oil Chem. Soc. Vol. 72, Pp. 1155-1160. 1995.

[15] T.A., Foglia, L.L. Nelson, R.O. Dunn, and W.N. Marmer, “Low-Temperature Properties of Alkyl Esters of Tallow and Grease”, J. Am. Oil Chem. Soc. Vol. 74, Pp. 951-955. 1997.

[16] K. Heikal Ebtisam, A. Khalil Salah, and K. Abdou Ismaeil. "Jatropha Bio-Diesel Production Technologies". International Journal of Bioscience, Biochemistry and Bioinformatics, Vol. 3, No. 3, May 2013.

[17] R Alcantara; J. Amores, L. Canoira, E. Fidalgo, M. J. Franco, A., Navarro. "Catalytic production of biodiesel from soy-bean oil, used frying oil and tallow". Biomass Bioenerg., Vol. 18, No. 6, Pp. 515-527. 2000.

[18] J. M Encinar; J. F. Gonzalez; A. Rodriguez-Reinares. "Biodiesel from used frying oil. Variables affecting the yields and characteristics of the biodiesel". Ind. Eng. Chem. Res., Vol. 44, No. 15, Pp. 5491-5499. 2005.

[19] E. Lotero, Y. Liu, D. E. Lopez, K. Suwannakarn, D. A. Bruce, and J. G. Goodwin, Jr. "Synthesis of Biodiesel via Acid Catalyst Ind". Eng. Chem. Res. Vol. 44, Pp. 5353-5363, 2005.

[20] A. C. Pinto, L. N. Guarieiro, M. J. Rezende, N. M. Ribeiro, Torres, E. A.; Lopes, W. A.; Pereira, P. A.; Andrade, J. B. "Biodiesel: An overview”. J. Brazil. Chem. Soc., Vol. 16, (6B), Pp. 1313-1330, 2005.

[21] P. Felizardo, M. J. Correia, I. Raposo, J. F. Mendes, R. Berkemeier, J. M., Bordado. "Production of biodiesel from waste frying oils". Waste Manage., Vol. 26, No. 5, Pp. 487-494, 2006.

[22] W. Zhou; D. G. B., Boocock. "Phase behavior of the base-catalyzed transesterification of soybean oil”. J. Am. OilChem. Soc., Vol. 83, No. 12, Pp. 10411045. 2006.

[23] X. Yuan, J. Liu, G. Zeng, J. Shi, J. Tong, G., Huang. Optimization of conversion of waste rapeseed oil with high FFA to biodiesel using response surface methodology. Renew. Energ., Vol. 33, No. 7, Pp. 1678-1684. 2008.

[24] I Yohei and S Shiro. A new process for catalyst-free production of biodiesel using supercritical methyl acetate. Fuel, Vol. 88, No. 7, Pp. 1307-1313. 2009.

[25] E.I. Bello, and M. Agge, "Biodiesel Production from Ground Nut Oil". Journal of Emerging Trends in Engineering and Applied Sciences (JETEAS), Vol. 3, No. 2, Pp. 276-280. (C) Scholarlink Research Institute Journals, (ISSN: 2141-7016), 2012.

[26] M.J. Haas and T. A. Foglia. "Biodiesel Production. Chapter Four". In The Biodiesel Handbook (Ed.) Gerhard Knothe, Jon Van Gerpen and Jürgen Krahl. Champaign, Illinois. Copyright (C) 2005 AOCS Press. 2005

[27] N. Saifuddin; K. H. Chua. "Production of ethyl ester (Biodiesel) from used frying oil: Optimization of transesterification process using microwave irradiation”. Malays. J. Chem., Vol. 6, No. 1, Pp. 77- 82, 2004.

[28] M., A., Hanna, L. Isom and J. Campbell. "Biodiesel: Current perspectives and future”. Journal of Scientific \& Industrial Research. Vol. 64, pp.854-857, 2005.

[29] J.M. Encinar, J.F. Gonzalez and A. Rodriguez-Reinares, Ethanolysis of used frying oil. Biodiesel preparation and characterization, Fuel Pro. Techno, 88, 513-522. 2007.

[30] J. Dupont, P. A. Z. Suarez, M. R. Meneghetti, S. M. P., Meneghetti. "Catalytic production of biodiesel and diesel-like hydrocarbons from triglycerides". Energy \& Environmental Science, Vol. 2, Pp. 1258-1265, 2009.

[31] A., Refaat, "Different techniques for the production of biodiesel from waste vegetable oil". Int. J. Environ. Sci. Tech., Vol. 7, No. 1, Pp. 183-213, Winter 2010 ISSN: 1735-1472. 2010

[32] V. Makareviciene, and P. Janulis, "Environmental effect of rapeseed oil ethyl ester". Renewable Energy, Vol. 28, pp. 2395-2403, ISSN 0960-1481, 2003.

[33] A. Demirbas, "Current advances in alternative motor fuels". Energy Explore Exploit; Vol. 21, Pp. 475-487, 2003b.

[34] Y.M. Sani, W.M.A.W. Daud and A.R. Abdul Aziz (December 3rd 2012). "Biodiesel Feedstock and Production Technologies: Successes, Challenges and Prospects", Biodiesel Zhen Fang, Intech0pen, DOI: 10.5772/52790. 2012.

[35] W. Zhou, S.K. Konar, D.G.V. Boocock, "Ethyl esters from the single-phase base-catalyzed ethanolysis of vegetable oils". J. Am. Oil Chem. Soc. Vol. 80, Pp. 367-371, 2003.

[36] N. C. Om Tapanes, D. A. Gomes Aranda, de Mesquita Carneiro, J. W.; Ceva Antunes, O. A. "Transesterification of Jatropha curcas oil glycerides: Theoretical and experimental studies of biodiesel reaction". Fuel, Vol. 87, No. 10-11, Pp. 2286-2295, 2008.

[37] F. Haigh Kathleen, T. Vladisavljević Goran, C. Reynolds James, N. Zoltan and S. Basudeb.“Kinetics of the pre-treatment of used cooking oil using Novozyme 435 for biodiesel production". Chemical Engineering Research and Design. Vol. 92, No. 4,Pp. 713-719, 2014.

[38] J. Kathlene, G. Rajesh, CM. Lekha, D. Ajay Kumar. "Solid acid catalyzed biodiesel production from waste cooking oil". Applied Catalyst B: Environmental. Vol. 85, No. 1-2, Pp. 86-91, 2008.

[39] X. Z., Liang, H. Q. Xiao, and C. Z., Qi, "Efficient procedure for biodiesel synthesis from waste oils using novel solid acidic ionic liquid polymer as catalysts". Fuel Processing Technology. Vol. 110, Pp. 109-113, 2013. 
[40] B. Y., Wang, S. F., Li, S. J., Tian, R. H. Feng, and Y. L., Meng, "A new solid base catalyst for the transesterification of rapeseed oil to biodiesel with methanol". Fuel, Vol. 104, Pp. 698-703, 2013.

[41] A. Srivastava, and R. Prasad, “Triglycerides-based diesel fuels”. Renewable Sustainable Energy Rev. Vol. 4, Pp. 111-133, 2000.

[42] K. Narasimharao, L. Adam, and W. Karen. "Catalysts in Production of Biodiesel: A Review”. Journal of Biobased Materials and Bioenergy, Vol. 1, 1$12,2007$.

[43] AF. Roseli, M. TP. Anna Leticia and P. Kil Jin. "Biodiesel Production and Quality". Biofuel's Engineering Process Technology, InTech, Brazil. ISBN 978-953-307-480-1, 2011.

[44] A. George, Z. Ypatia, S. Stamoulis and K. Stamatis. "Transesterification of Vegetable Oils with Ethanol and Characterization of the Key Fuel Properties of Ethyl Esters". Energies, Vol. 2, Pp. 362-376; doi:10.3390/en20200362. 2009.

[45] J.M. Marchetti, and A.F. Errazu, "Biodiesel production from acid oils and ethanol using a solid basic resin as catalyst". Biomass \& Bioenergy, Vol. 34, Pp. 272-277, ISSN 0961-9534, 2010.

[46] A. V. Tomasevic, S. S., Siler-Marinkovic. “Methanolysis of used frying oil”. Fuel Process Tech., Vol. 81, No. 1, Pp. 1-6, 2003.

[47] M. P. Dorado, E. Ballesteros, M. Mittelbach, F. J., Lopez. "Kinetic parameters affecting the alkali-catalyzed transesterification process of used olive oil". Energ. Fuel., Vol. 18, No. 5, Pp. 1457-1462, 2004.

[48] A. A. Refaat, and S. T., El Sheltawy. "Comparing three options for biodiesel production from waste vegetable oil”. WIT Transactions on Ecology and the Environment, Waste Management and the Environment IV, Vol. 109, WIT Press, Pp. 133-140, 2008.

[49] A. Gupta, S. K. Sharma, Pal Toor, A. “Production of biodiesel from waste soybean oil”. J. Petrotech Soc., Vol. 4, No. 1, Pp. 40-45, 2007.

[50] A., Demirbas. “Biodiesel from waste cooking oil via base-catalytic and supercritical methanol transesterification”. Energ. Convers. Manage., Vol. 50, No. 4, Pp. 923-927, 2009.

[51] D. Y. C. Leung; Y., Guo. “Transesterification of neat and used frying oil: Optimization for biodiesel production”. Fuel Process Tech., Vol. 87, No. 10, Pp. 883-890, 2006.

[52] A. B. Chhetri, K. C. Watts, M. R., Islam. “Waste cooking oil as an alternate feedstock for biodiesel production”. Energies, Vol. 1, No. 1, Pp. 3-18, 2008.

[53] X. Meng; G. Chen; Y., Wang, (2008). Biodiesel production from waste cooking oil via alkali catalyst and its engine test. Fuel Process Tech., 89 (9), 851-857.

[54] A. Singh; B. He; J. Thompson; J. Van Gerpen. "Process optimization of biodiesel production using different alkaline catalysts". Appl. Eng. Agr., Vol. 22, No. 4, Pp. 597-600, 2006.

[55] X. Deng, Z. Fang, and Y. H., Liu, “Ultrasonic transesterification of Jatropha curcas L. oil to biodiesel by a two-step process". Energy Conver. Manage., Vol. 51, Pp. 2802-2807, 2010.

[56] A Hayyan, MZ Alam, ME Mirghani, NA Kabbashi, NI Hakimi, YM Siran, S Tahiruddin. "Sludge palm oil as a renewable raw material for biodiesel production by two-step processes". Bioresour. Technol., Vol. 101, Pp. 7804-7811, 2010a.

[57] S Yves, A Diamantis and F Stéphane. Catalyst technology for biofuel production: Conversion of renewable lipids into biojet and biodiesel. OCL 2013, 20(5) D502. DOI: $10.1051 /$ ocl/2013023.

[58] Q Jing-Juan, L Jin-Qing and F Hong-Quan. "One-step production of biodiesel from waste cooking oil catalysed by SO3H-functionalized quaternary ammonium ionic liquid". Current Science, Vol. 110, No. 11, 10 June 2016.

[59] J. Kansedo, K. T. Lee, and S. Bhatia, "Biodiesel production from palm oil via heterogeneous transesterification”. Biomass \& Bioenergy, Vol. 33, pp. 271-276, ISSN 0961-9534, 2009.

[60] M. M. Rahman Talukder, J. C. Wu, S. K. Lau, L. C. Cui, G. Shimin and A. Lim. "Comparison of Novozym 435 and Amberlyst 15 as Heterogeneous Catalyst for Production of Biodiesel from Palm Fatty Acid Distillate". Energy Fuels, Vol. 23, No. 1, Pp. 1-4. DOI: 10.1021/ef8006245. 2009.

[61] H. Kazemian, B. Turowec, M. N. Siddiquee, and Rohani, S., "Biodiesel production using cesium modified mesoporous ordered silica as heterogeneous base catalyst". Fuel, 2013, 103, 719-724.

[62] R. Leyva-Ramos, A. Jacobo-Azuara, PE Diaz-Flores, RM Guerrero-Coronado, J. Mendoza-Barron, MS Berber-Mendoza. "Adsorption of chromium (VI) from an aqueous solution on a surfactant-modified zeolite". Colloids and Surfaces A physicochemical and Engineering aspects, Vol. 330, No. 1, Pp. 3541, 2008.

[63] S. Qing, Y. Bolun, Y. Hong and Z. Gangli. "Synthesis of biodiesel from soybean oil and methanol catalyzed by zeolite beta modified with La3+". Catalyst Communications, Vol. 8, No. 12, Pp. 2159-2165. DOI: 10.1016/j.catcom.2007.04.028. 2007.

[64] B. Freedman, R.O. Butterfield, and E.H. Pryde, “Transesterification kinetics of soybean oil”. Journal of the American Oil Chemists Society, Vol. 63, Pp. 1375-1380, ISSN 1558-9331. 1986.

[65] A. W., Schwab, M. O. Bagby, and B. Freedman. "Preparation and properties of diesel fuels from vegetable oils". Fuel. Vol. 66, No. 10, Pp. 1372-1378. 1987.

[66] K. Liu. "Preparation of fatty acid methyl esters for gas chromatographic analysis of lipids in biological materials". JAOCS, Vol. 71, No. 11, Pp. 1179$1187,1994$.

[67] Y. Zhang, M. A. Dube, D. D. McLean, M., Kates. "Biodiesel production from waste cooking oil: 2. Economic assessment and sensitivity analysis". Bioresour. Tech., Vol. 90, No. 3, Pp. 229-240 (12 pages). 2003.

[68] U. Soriano Jr. Nestor, V. Richard and S. Argyropoulos Dimitris. "Biodiesel synthesis via homogeneous Lewis acid-catalyzed transesterification". Fuel. Vol. 88, Pp. 560-565, 2009.

[69] M. Shahid Ejaz and J. Younis; "Production of biodiesel: A technical review”; Renewable and Sustainable Energy Reviews. Vol. 15, Pp. 4732- 4745, 2011.

[70] Y. Wang, S. Ou, P. Liu, F. Xue, S. Tang. "Comparison of two different processes to synthesize biodiesel by waste cooking oil". J. Mol. Catal. A-Chem., Vol. 252, No. 1-2, Pp. 107-112, 2006. 
[71] B. Freedman, E. H. Pryde, and T. L. Mounts. "Variables affecting the yields of fatty esters from transesterified vegetable oils". JAOCS, Vol. 61, No. 10, Pp. 1638-1643. 1984.

[72] J. Van Gerpen, B. Shanks, R. Pruszko, D. Clements, G. Knothe, "Biodiesel Production Technology August 2002-January 2004, NREL/SR-510-36244, 2004.

[73] G. Yin Yu, C. Wen Wei, L. Hanwu, L. Yuhuan, L. Xiangyang and R. Roger. "Optimization of transesterification conditions for the production of fatty acid methyl ester (FAME) from Chinese tallow kernel oil with surfactant-coated lipase". Biomass and Bioenergy. Vol. 33, No. 2, Pp. 277-282, 2009.

[74] R. Sridharan, I. M. Mathai, “Transesterification reactions”. Sci. Ind. Resour. Vol. 33, Pp. 178-187, 1974.

[75] Y., Kawahara, and T. Ono, "Process for Producing Lower Alcohol Esters of Fatty Acids, U.S. Patent, Vol. 4, No. 164, Pp. 506. 1979.

[76] M. Canakci and J. Van Gerpen. "Biodiesel Production Via Acid Catalyst”. American Society of Agricultural Engineers 0001-2351 / 1999 / 4205-1203. Vol. 42, No. 5, Pp. 1203-1210, 1974.

[77] M.J., Goff, N.S. Bauer, S. Lopes, W.R. Sutterlin, and G.J. Suppes, “Acid-Catalyzed Alcoholysis of Soybean Oil”, J. Am. Oil Chem. Soc. Vol. 81, Pp. 415-420, 2004.

[78] 0. Ferrero Gabriel, F. Almeida Manuel, C.M. Alvim-Ferraz Maria and M. Dias Joana. "Glycerol-enriched heterogeneous catalyst for biodiesel production from soybean oil and waste frying oil”. Energy Conversion and Management. Vol. 89, 1 January 2015, Pp. 665-671, 1974.

[79] J.M., Marchetti, V. U. Miguel, and A. F. Errazu, "Heterogeneous esterification of oil with high amount of free fatty acids". Fuel, Vol. 86, pp. 906-910, ISSN 0016-2361. 2007.

[80] L. C Meher, V. S. Dharmagadda, S. N. Naik, "Optimization of alkali-catalyzed transesterification of Pongamia pinnata oil for production of biodiesel”. Bioresour Technol. Aug; Vol. 97, No. 12, Pp. 1392-97, 2006.

[81] J.; Hancsók, F.; Kovács, M., Krár. "Production of vegetable oil fatty acid methyl esters from used frying oil by combined acidic/alkali transesterification". Petrol. Coal., Vol. 46, No. 3, Pp. 36-44, 2004.

[82] T.; Issariyakul, M. G.; Kulkarni, A. K.; Dalai, N. N. Bakhshi. "Production of biodiesel from waste fryer grease using mixed methanol/ethanol system". Fuel Process Tech., Vol. 88, No. 5, Pp. 429-436, 2007.

[83] G. Cayli, S., Küsefoglu. "Increased yields in biodiesel production from used cooking oils by a two step process: Comparison with one step process by using TGA". Fuel Proc. Tech., Vol. 89, No. 2, Pp. 118-122, 2008.

[84] W. N. N. Wan Omar, N. Nordin, M. Mohamed, N. A. S., Amin. "A two-step biodiesel production from waste cooking oil: Optimization of pre-treatment step". J. Appl. Sci., Vol. 9, No. 17, Pp. 3098-3103, 2009.

[85] S. V. Ghadge; H. Raheman. "Biodiesel production from mahua (Madhuca indica) oil having high free fatty acids". Biomass. Bioenerg. Vol. 28, Pp. 601-605. 2005.

[86] V.B. Veljković, S.H. Lakićević, O.S. Stamenković, Z.B. Todorović and M.L.Lazić. “Biodiesel production from tobacco (Nicotiana tabacumL.) seed oil with a high content of free fatty acids". Fuel. Vol. 85, No. 17-18, December 2006, Pp. 2671-2675, 2006.

[87] P.K. Sahoo, L.M. Das, M.K.G. Babu and S.N. Naik. "Biodiesel development from high acid value polanga seed oil and performance evaluation in a CI engine". Fuel. Vol. 86, No. 3, February 2007, Pp. 448-454, 2007.

[88] M.; Hayyan, F.S. Mjalli, M.A. Hashim, I.M. AINashef, "A novel technique for separating glycerine from palm oil-based biodiesel using ionic liquids". Fuel Process. Technol. Vol. 91, Pp. 116-120, 2010b.

[89] A., Khan, "Research into Biodiesel Kinetics and Catalyst Development". Ph D thesis, The university of Queensland, Brisbane, Queensland, Australia. 2002.

[90] C.D., Baertsch, K.T., Komala, Y.H., Chua, and E., Iglesia, "Genesis of Bronsted acid sites during dehydration of 2-butanol on tungsten oxide catalysts" J. Catal. Vol. 205, No. 44, 2002.

[91] H.E. Hoydonckx, D.E. De Vos, S.A. Chavan, and P.A. Jacobs, "Esterification and Transesterification of Renewable Chemicals". Topics in Catalyst. Vol. 27, No. 83, 2004.

[92] J., Macht, C.D., Baertsch, M., May-Lozano, S.L., Soled, Y., Wang, and E., Iglesia, "Support effects on Bronsted acid site densities and alcohol dehydration turnover rates on tungsten oxide domains" J. Catal. Vol. 227, Pp. 479, 2004.

[93] M., Di Serio, R., Tesser, M., Dimiccoli, F., Cammarota, M., Nastasi, and E., Santacesaria, "Synthesis of biodiesel via homogeneous Lewis acid catalyst" J. Mol.Catal. A. Vol. 239, Pp. 111-115, 2005.

[94] M. I. Al-Widyan, A. O., Al-Shyoukh. "Experimental evaluation of the transesterification of waste palm oil into biodiesel”. Bioresour. Tech., Vol. 85, No. 3, Pp. 253-256, 2002.

[95] M. J. Nye, T. W. Willianson, S. Deshpande, J. H. Schrader, W. H. Snively, T. P. Yurkewich, C. R. Frech, “Conversion of used frying oil to diesel fuel by transesterification: preliminary test". J. Am. Oil Chem. Soc, Vol. 60, Pp. 1598-1601, 1983.

[96] Z. J. Predojević. “The production of biodiesel from waste frying oils: A comparison of different purification steps”. Fuel, Vol. 87, No. 17-18, Pp. 3522$3528,2008$.

[97] A. Banerjee and R. Chakraborty. "Parametric sensitivity in transesterification of waste cooking oil for biodiesel production- A review". Resources, Conservation and Recycling. Vol. 53, No. 9, July 2009, Pp. 490-497, 2008.

[98] X1 Miao, Q Wu. "Biodiesel production from heterotrophic microalgal oil”. Bioresour Technol. Apr; Vol. 97, No. 6, Pp. 841-846, 2006.

[99] MGM. D’Oca, CV. Vie^gas, JS. Lemões, EK. Miyasaki, JA. Moro'n-Villarreyes, EG. Primel, PC. Abreu; “Production of FAMEs from several microalgal lipidic extracts and direct transesterification of the Chlorella pyrenoidosa". Biomass \& Bioenergy, Vol. 35, Pp. 1533-1538, 2011.

[100] M. W. Formo. "Ester reactions of fatty materials". JAOCS. Vol. 31, No. 11, Pp. 548-559, 1954.

[101] B., Freedman, and E. H. Pryde. "Fatty esters from vegetable oils for use as a diesel fuel". In Vegetable Oil Fuels — Proc. Int. Conf. on Plant and Vegetable Oils as Fuels, Pp. 117-122, Fargo, N.D., 2-4 August. St. Joseph, Mich.: ASAE. 1982. 
[102] M. J., Nye, and P. H. Southwell. "Conversion of rapeseed oil to esters for use as diesel fuel. In Proc. 5th Canadian Bioenergy Res. and Develop". Seminar, Pp. 487-490. London, England: Elsevier Applied Science. 1984.

[103] Fan X, Wang X and Chen F. "Biodiesel Production from Crude Cottonseed Oil: An Optimization Process Using Response Surface Methodology". The Open Fuels and Energy Science Journal, Vol. 4, Pp. 1-8, 2011.

[104] P. F. Kusy. "Transesterification of vegetable oils for fuels". In Vegetable Oil Fuels — Proc. Int. Conf. on Plant and Vegetable Oils as Fuels, Pp. 127137, Fargo, N.D., 2-4 August. St. Joseph, Mich.: ASAE. 1982.

[105] L. Canoira, R. Alcántara, M. J. García-Martínez, J Carrasco,. "Biodiesel from Jojoba oil-wax: transesterification with methanol and properties as a fuel". Biomass and Bioenergy. Vol. 30, No.1, Pp.76-81, 2006.

[106] G., T. Jeong, H., S. Yang, and D., H Park. "Optimization of transesterification of animal fat ester using response surface methodology". Bioresour Technol. Jan; 100(1), Pp. 25-30, 2009.

[107] D. G. B., Boocock, S. K., Konar, and H. Sidi., "Phase diagrams for oil/methanol/ether mixtures”. JAOCS, Vol. 73, No. 10, Pp. 1247-1251, 1996.

[108] A., N. Phan, and T. M., Phan. “Biodiesel production from waste cooking oils”. Fuel. Vol. 87, No. 17-18, Pp. 3490-3496, 2008.

[109] GLN Rao, S Sampath, K Rajagopal. "Experimental studies on the combustion and emission characteristics of a diesel engine fuelled with used cooking oil methyl ester and its diesel blends". Int J Appl Sci Technol; Vol. 4, No. 2, Pp. 64-70, 2007.

[110] K Yanagimoto, H Ochi, KG Lee, T Shibamoto. "Antioxidative activities of fractions obtained from brewed coffee”. J Agric Food Chem. 2004 Feb 11; Vol. 52, No. 3, Pp. 592-6, 2004

[111] P, O Campo, Y Zhao, MT Suidan, AD Venosa, and GA Sorial. "Biodegradation kinetics and toxicity of vegetable oil triacylglycerols under aerobic conditions". Chemosphere 26 Mar 2007, Vol. 68, No. 11, Pp. 2054-2062, 2007.

[112] H. Mebrahtu, A. Araya, A. Nigist. "Investigation of Waste Coffee Ground as a Potential Raw Material for Biodiesel Production". International Journal Of Renewable Energy Research. Vol.3, No.4, 2013

[113] D. Darnoko; M Cheryan. "Kinetics of palm oil transesterification in a batch reactor". J. Am. Oil Chem. Soc. Vol. 77, Pp. 1263-1267. 2000.2007.

[114] R. Umer, A. Farooq, R. M Bryan and A. Samia. "Production of sunflower oil methyl esters by optimized alkali-catalyzed methanolysis". B Iomass And Bioenergy. Vol. 32, Pp. 1202-1205, 2008.

[115] N. Saifuddin, A Z. Raziah and H. Nor farah. "Production of Biodiesel from High Acid Value Waste Cooking Oil Using an Optimized Lipase Enzyme/Acid-Catalyzed Hybrid Process”. E-Journal of Chemistry. Vol. 6(S1), S485-S495. ISSN: 0973-4945; CODEN ECJHAO, 2009.

[116] P. Felizardo, J., Machado, D., Vergueiro, M.J.N., Correia, J.M., Bordado, "High Free Fatty Acids oils for biodiesel production", Proceedings of the 10th International Chemical and Biological Engineering Conference-Chempor 2008, Braga, Portugal, 4-6 September, Pp. 1220 -1225, 2008.

[117] T. Mata, A. Mendes, N. Caetano, A. Martins, "Properties and sustainability of biodiesel from animal fats and fish oil", Chemical Engineering Transactions, Vol. 38, Pp. 175-180. DOI: 10.3303/CET1438030. 2014.

[118] J. Surachai. "Preparation of Vegetable Oil as Biodiesel Feedstock Via Re-Esterification: A Suitable Catalyst". 2015 International Conference on Alternative Energy in Developing Countries and Emerging Economies. Energy Procedia. Vol. 79, Pp. 143 -148, 2015.

[119] H.N., Basu, and M.E. Norris, "Process for the Production of Esters for Use as a Diesel Fuel Substitute Using Non-Alkaline Catalyst, U.S. Patent $5525126 \mathrm{~A}, 1996$.

[120] X. Z., Liang, G. Z., Gong, H. H. Wu, and J. G., Yang, "Highly efficient procedure for the synthesis of biodiesel from soybean oil using chloroaluminate ionic liquid as catalyst". Fuel, Vol. 88, Pp. 613-616, 2009. 